\title{
Shielded field emission EPMA for microanalysis of radioactive materials
}

\author{
R Restani ${ }^{1}$ and A Wälchli \\ Paul Scherrer Institut, Hotlaboratory Division, CH-5232 Villigen PSI \\ E-mail: renato.restani@psi.ch
}

\begin{abstract}
A standard Jeol 8500F electron probe microanalyzer (EPMA) with field emission gun (FEG) has been installed in a lead shielded cabin of the laboratory and customized for remote control. The wavelength-dispersive X-ray spectrometers (WDS) have been additionally shielded against $\beta, \gamma$-radiation with tungsten alloy modules. These measures have proven to be very effective for the examination of specimens with an activity of less than $20 \mathrm{GBq}{ }^{137} \mathrm{Cs}$. The background intensity is dependent on crystal type, spectrometer and sample position. The efficiency of the spectrometer with Xe-sealed counter is higher but also its sensitivity to the specimen's $\gamma$-radiation than the $\mathrm{Ar} / \mathrm{CH}_{4}$ flow counter. The possibility of applying high beam currents increases the peak-to-background ratio for the analysis of low concentrations in the active sample. The high electron beam density of the FE-gun allows for the recording of high resolution elemental X-ray maps in the range of a few tenths of a micrometre at even medium acceleration voltage and thus short acquisition time. It is thus a valuable instrument in post irradiation examinations of spent fuel rods and materials irradiated by other sources.
\end{abstract}

\section{Introduction}

Electron probe microanalysis (EPMA) is a versatile method in post-irradiation examinations for materials characterisation. The necessity to shield the wavelength-dispersive X-ray spectrometers (WDS) against strong $\beta, \gamma$-radiation has already been successfully handled in the late seventies with the Cameca MS 46 and was already used for dissolved fission gas analysis in irradiated fuel [1-3]. The examination with the Jeol 733 required a sophisticated sample preparation to very small samples [4]. In the eighties and early nineties followed the shielded Camebax R [5,6] and SX-50R [7, 8] respectively. The last one is equipped with a massive stage shielding and spectrometers separated from the specimen chamber by narrow tubes with window sleeves. The large Rowland circle of $180 \mathrm{~mm}$ offers space for additional spectrometer shielding and a big detector-crystal-to-specimen distance. The electron gun has been equipped with a tungsten filament. The successor instrument Cameca SX-100R, just a few years on the market, can also be equipped with a $\mathrm{LaB}_{6}$ cathode. A field emission gun (FEG) with even smaller probe diameter and higher current at low accelerating voltage is not yet provided due to constructive changes necessary related to the vacuum system.

It has been our incentive to select and modify a FEG EPMA for the examination of nuclear materials in cooperation with the necessary manufacturers and partners to accomplish this task which were found in Jeol Germany and remX GmbH.

\footnotetext{
1 To whom any correspondence should be addressed.
} 
EMAS 2011: 12th European Workshop on Modern Developments in Microbeam Analysis

IOP Publishing IOP Conf. Series: Materials Science and Engineering 32 (2012) 012022 doi:10.1088/1757-899X/32/1/012022

\section{Design of shielded FEG EPMA}

The selected EPMA is a standard Jeol $8500 \mathrm{~F}$ with Schottky field emission gun. The instrument had to be installed in a lead shielded cabin at the end of a sample preparation cell line (figure 1). Jeol Germany divided the electronics cabinets and installed long distance cables with the appropriate signalling to the control desk outside the cabin. Afterwards modular internal shields made of tungsten alloy on the stage, at spectrometers ports around the specimen chamber and around the pole shoe were constructed by the project leader, remX GmbH (table 1, figures 2 and 3). The relatively small WDS-spectrometers with $140 \mathrm{~mm}$ Rowland circle could not be additionally shielded. The contractor organized also the optical window, the motorized aperture from Deben UK Ltd., and was also engaged in infrastructural equipments. The shielded sample holder is loaded with the polished sample in the adjacent cell and transferred to the cabin via a rotary gate and put in place by cell manipulators in the airlock chamber of the EPMA. These manipulators also operate the rod manipulator of the EPMA to transfer the sample into the recipient.

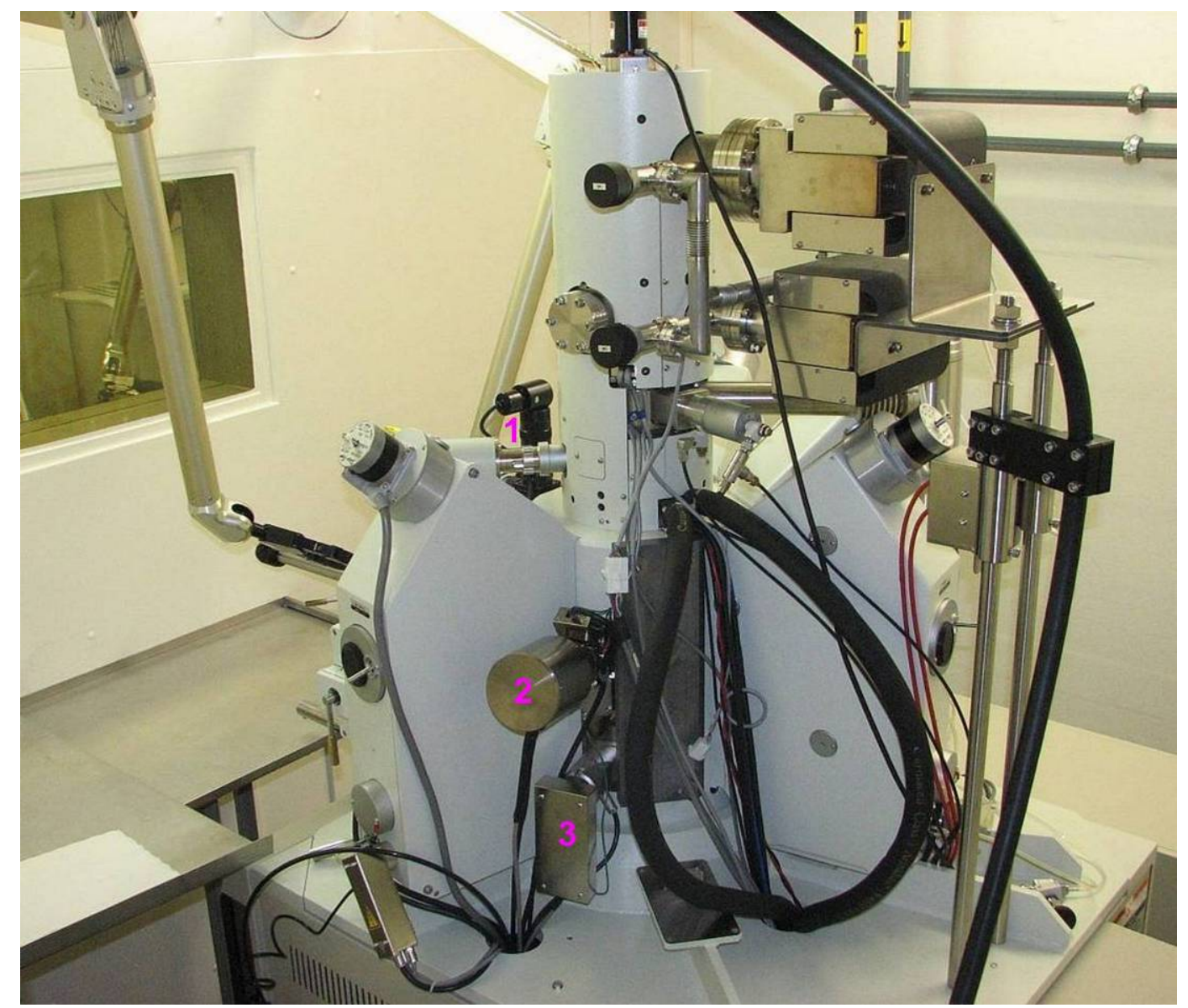

Figure 1. Modified and shielded field emission Jeol 8500F EPMA with 4 WDSspectrometers ( 2 of them hidden on photo) in a lead shielded cabin (back view). 1: optical microscope; 2: SE-detector; 3: BSE-detector

A compromise between the driveway of the stage and spectrometers and the extent and thus effectiveness of the shielding had to be found. The windowless space between the spectrometers and chamber for the crystal drive was fit to the dimensions of the crystal frame and is the only opening. 
EMAS 2011: 12th European Workshop on Modern Developments in Microbeam Analysis

IOP Publishing IOP Conf. Series: Materials Science and Engineering 32 (2012) 012022 doi:10.1088/1757-899X/32/1/012022

Table 1. Internal EPMA shielding of JEOL $8500 \mathrm{~F}$ with tungsten alloy (W content $>90 \mathrm{wt} \%$, density $\left.18 \mathrm{~g} / \mathrm{cm}^{3}\right)$.

\begin{tabular}{|l|c|c|c|}
\hline Shielding place & $\begin{array}{c}\text { Port between } \\
\text { spectrometer } \\
\text { and chamber }\end{array}$ & $\begin{array}{c}\text { Plates around } \\
\text { pole shoe }\end{array}$ & $\begin{array}{c}\text { Stage + specimen } \\
\text { holder }\end{array}$ \\
\hline Number of shielding units & 5 (vertical) & $\begin{array}{c}2 \text { (horizontal, including a } \\
2.5 \mathrm{~mm} \beta \text {-shield of Al) }\end{array}$ & 2 \\
\hline Height $(\mathrm{cm})$ & 15 & & 5 \\
\hline Width $(\mathrm{cm})$ & 8 & & 8 \\
\hline Depth $(\mathrm{cm})$ & 5 & & 13 \\
\hline Length $(\mathrm{cm})$ & & & \\
\hline Thickness $(\mathrm{cm})$ & & $1.5+0.5$ & \\
\hline
\end{tabular}

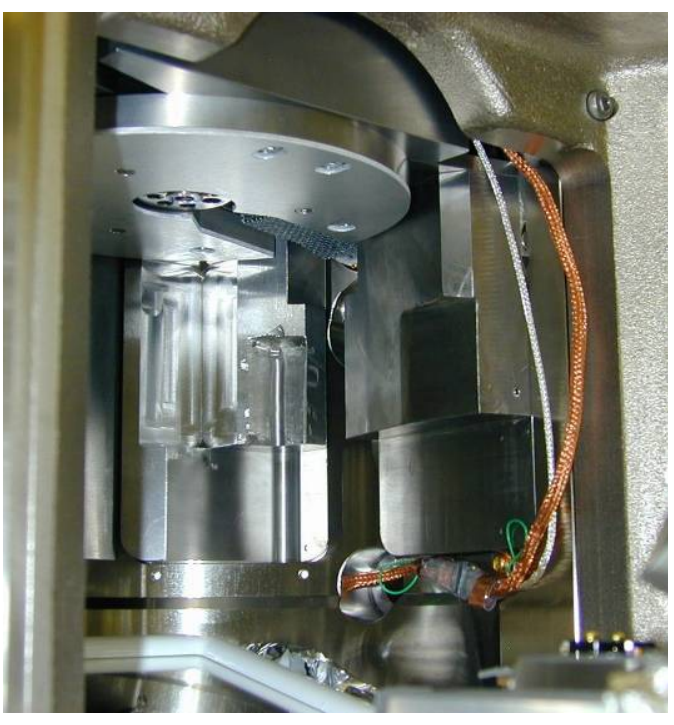

Figure 2. Specimen chamber with vertical tungsten alloy shield blocks at spectrometer ports and a tungstenaluminium plate around the pole piece.

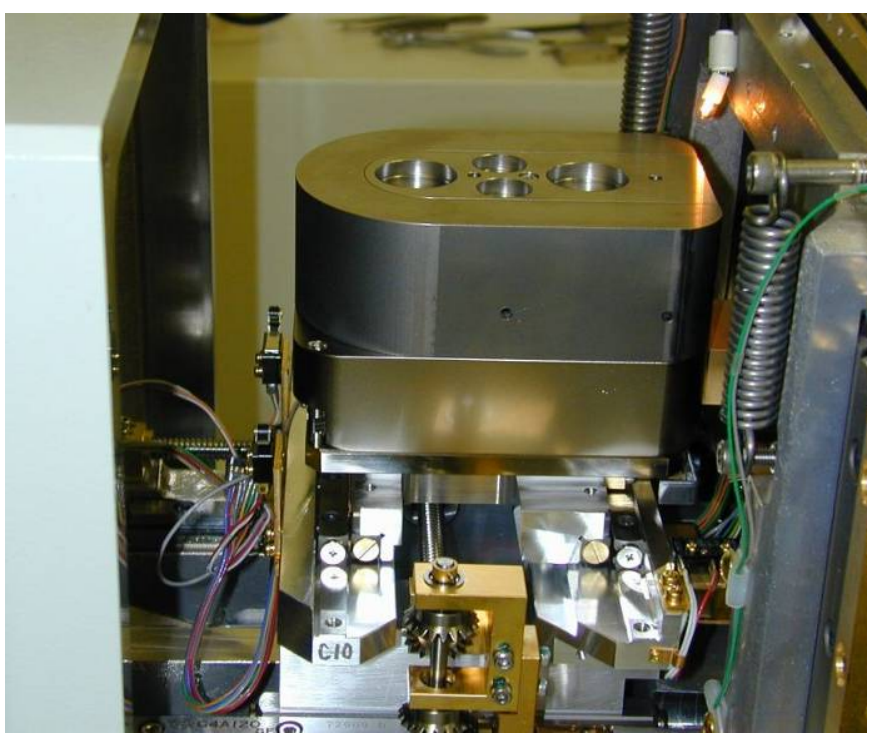

Figure 3. Shielded stage (horseshoe-shaped) with the shielded specimen holder inside containing drillings for 1-inch and $17 \mathrm{~mm}$ specimens. $\mathrm{X}-\mathrm{Y}-\mathrm{Z}$ axes drives underneath.

For the spectrometers the lower limit is at about $75 \mathrm{~mm}$ between sample and crystal (eq. Bragg angle $\sin \theta \approx 0.27)$. There are two spectrometers with LIF/PET diffracting crystals and sealed Xe-counters. For light elements two spectrometers with TAP/LDE1 and TAP/LDE2 crystals with $\mathrm{Ar} / \mathrm{CH}_{4}$ flow counters are attached.

\section{Effectiveness of shielding}

The effect of the tungsten module shields were tested with an encapsulated highly active fuel specimen $(\gamma$-source). The radiation background is mainly dependent on the shielding environment and the distance between detector and the active specimen. This means that the positions of the spectrometers, crystal-detector and sample are decisive but also the crystal and counter type have an influence. It proved that the rear spectrometers (pos. 3 and 4, spectrometers on the right side of figure 1) are better shielded than the ones in front at pos. 1 and 2 (figure 4). The dependency on the 
sample position is given in figure 5. It also shows that at certain border positions the background level can change in the opposite direction than is expected from the crystal-detector position.
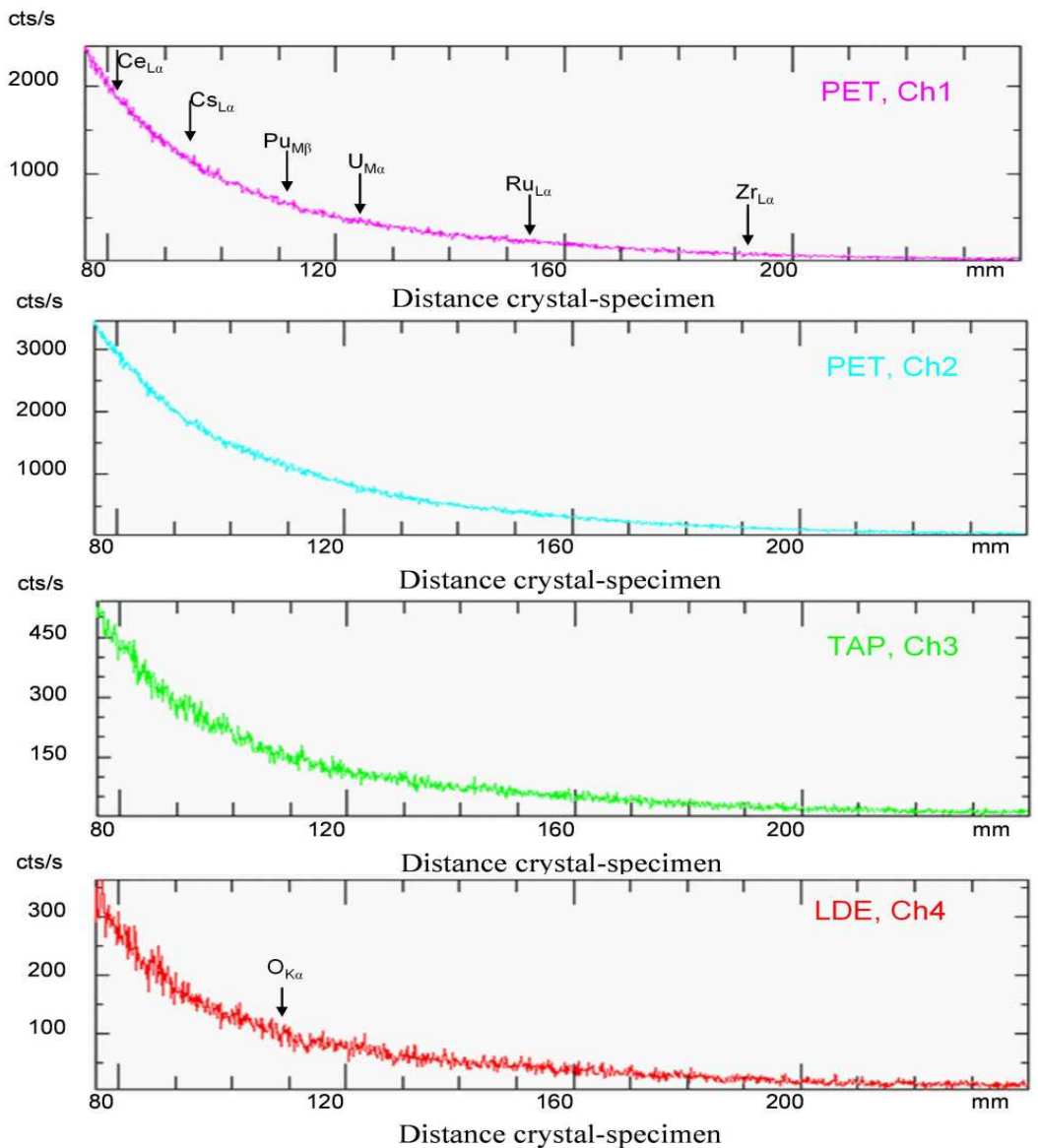

Figure 4. Radiation background measured on 4 spectrometers with a $\gamma$-source of $200 \mathrm{mGy} / \mathrm{h}$ in $0.1 \mathrm{~m}$. Channels 1 and 2 with Xecounters, channels 3 and 4 with $\mathrm{Ar} / \mathrm{CH}_{4}$. See theoretical positions of some X-ray lines, conversion: $\sin \theta=$ distance $(\mathrm{mm}) / 280$.

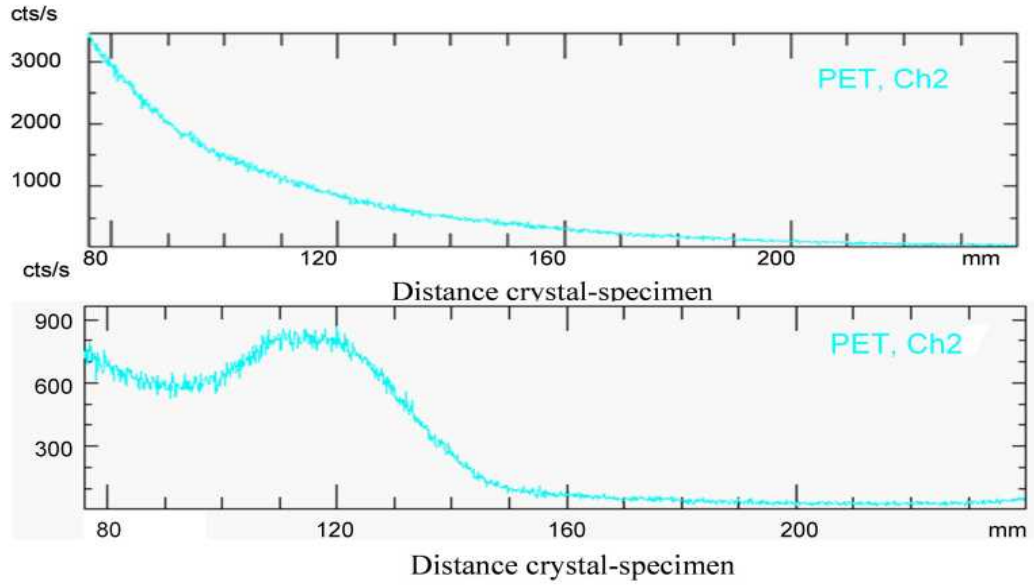

Figure 5. Background characteristics at 2 different sample positions measured with a $\gamma$-source of $200 \mathrm{mGy} / \mathrm{h}$ in $0.1 \mathrm{~m}$.

The benefit of the tungsten plate around the pole piece is shown on figure 6. A thin Al-plate screwed on the shielding (figure 2) to capture the electrons from $\beta$-decay and reduce the subsequent bremsstrahlung had no additional positive influence. 


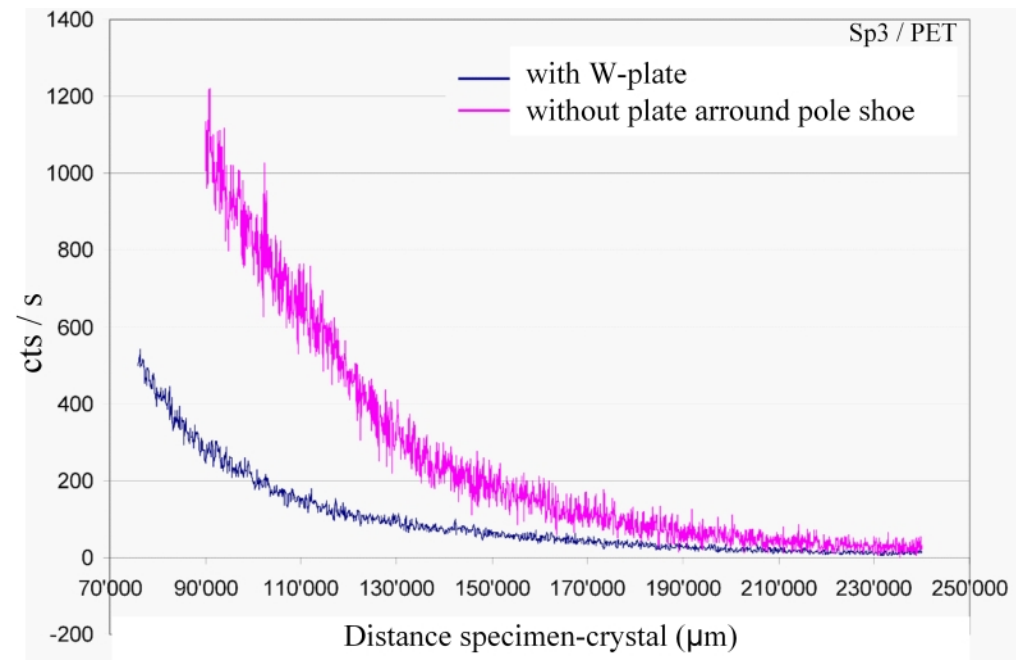

Figure 6. Effect of a $1.5 \mathrm{~cm}$ thick tungsten shield plate around the pole piece on the radiation background level of a rear spectrometer, mounted in addition to other shields ( $\gamma$-radiation source: $200 \mathrm{mGy} / \mathrm{h}$ in $0.1 \mathrm{~m})$.

The comparison of the background level for the different counters is given in figure 7 . The $\mathrm{Ar} / \mathrm{CH}_{4}$-counter is less susceptible than the Xe-counter. Nonetheless it was decided to maintain the Xe-counters for spectrometers with LIF/PET crystals because of its higher efficiency and often longer lifetime as no impurities could accidentally be brought in.

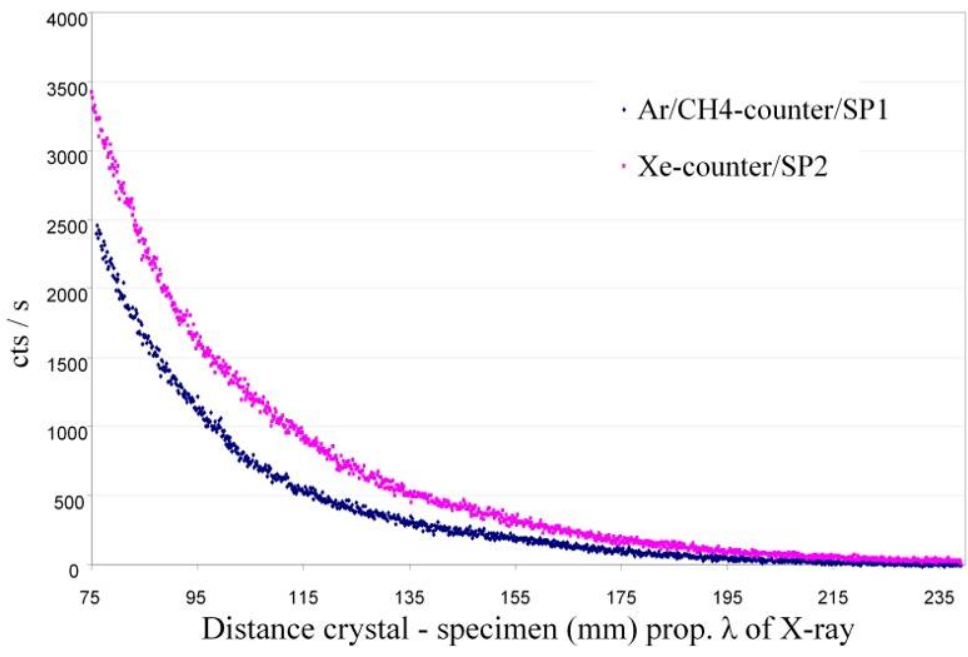

Figure 7. Sensitivity of different detectors to a $\gamma$-radiation source of $200 \mathrm{mGy} / \mathrm{h}$ in $0.1 \mathrm{~m}$.

The detector characteristics require to run the pulse height analyzer in the differential mode to further discriminate the radiation impact. An energy window of about $60 \%$ of the voltage range is typically applied. This means that the pulse height distribution must always be checked for each element and analysis setup to avoid pulse height depression and broadening. The result of all these measures is shown on a spectrum taken from a small irradiated $\mathrm{UO}_{2}$-fuel sample $\left(\approx 80 \mathrm{~mm}_{3}\right)$ which had an equivalent activity of $5 \mathrm{GBq}{ }^{137} \mathrm{Cs}$ (figure 8). The acquisition was recorded on a spectrometer with PET crystal applying a typically higher voltage and current and a medium bias. The rise in background due to the radiation which has about doubled for the higher energy characteristic X-rays is not too high to impede the quantitative measurement of the low content fission products. For the $\mathrm{Nd}$ L $\alpha$-line the background is at the limit as the detector is only partly shielded at this position (top end) but $\mathrm{Nd}$ can also be measured with the LIF crystal. The spectrometer efficiencies for typical 
element concentrations in an irradiated fuel are given in table 2. The spectral resolution with respect to the small Rowland circle is good but is of lower importance than the spectrometer efficiency achievable under radiation conditions. Nonetheless the number of fission products causes interferences from subordinate lines as well as from uranium satellites which must be accounted for in the microprobe analysis (figure 8). Also a careful selection of positions for background measurements has to be made which has to be adapted to the standardisation procedure as well. Often the background can only be measured on one side of the peak with linear or curved extrapolation depending on the background gradient (e.g., for $\mathrm{Pu}, \mathrm{Cs}, \mathrm{Nd}, \mathrm{Ce}, \mathrm{Ru}$ ).

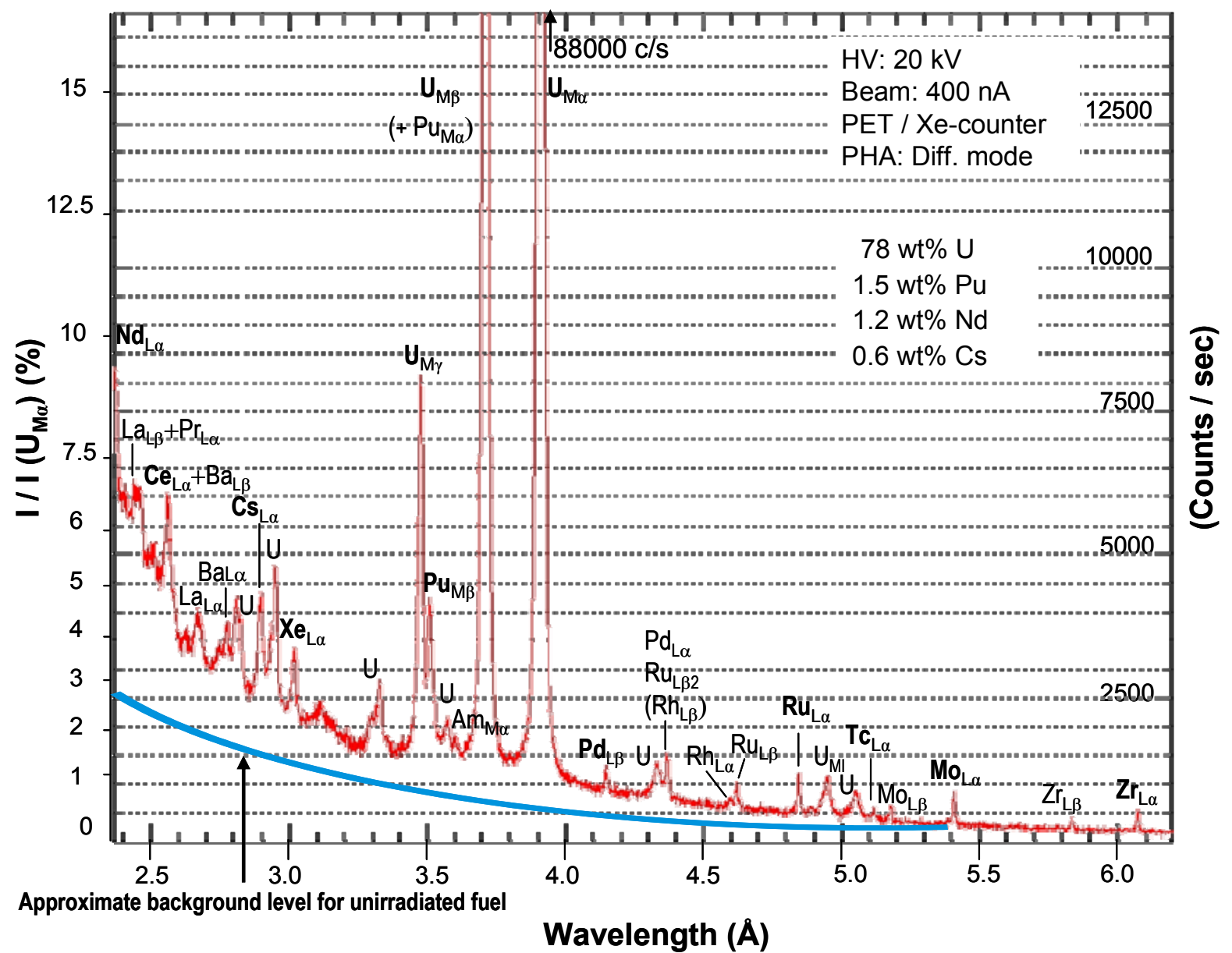

Figure 8. WDS-spectrum of a small high burn-up $\mathrm{UO}_{2}$-fuel piece (equiv. $5 \mathrm{GBq}{ }^{137} \mathrm{Cs}$ ) with peaks from $\mathrm{U}$ and its satellites, $\mathrm{Pu}$ and $\mathrm{Am}$ from the nuclear breeding reaction and the fission products. Left $\mathrm{Y}$-axis in percent of the $\mathrm{U} \mathrm{M} \alpha$ peak count rate. Background level increased due to radiation impact.

\section{Spatial resolution}

The advantage of the FE gun is the small probe diameter which is the limiting factor for scanning electron microscopy of the surface (SEM). The high beam density provides high X-ray signal yields important for elemental dot mapping and analysis at low accelerating voltage to further increase the resolution. For standard analysis it is however more important to limit the dwell time and the exposure time of the specimen to the electron beam for the sake of the delicate instruments components and particularly avoiding contamination with the volatile ${ }^{137} \mathrm{Cs}$. For a once-through 
Table 2. Spectrometer efficiency (PET) for an irradiated $\mathrm{UO}_{2}$-fuel specimen $(0.85 \mathrm{~g})$ with a burn-up of $64 \mathrm{MWd} / \mathrm{kgU}$, equiv. $5 \mathrm{GBq}{ }^{137} \mathrm{Cs} ; 50 \mathrm{mGy} / \mathrm{h}$ in $0.1 \mathrm{~m}$. Condition: $20 \mathrm{kV}, 350 \mathrm{nA}$.

\begin{tabular}{llll}
\hline \multicolumn{4}{c}{ Jeol 8500F shielded / PET crystal (Xe counter) } \\
\hline Element (wt\%), line & Peak/BG-ratio & Yield at 20kV c/s/nA) & $\begin{array}{l}\text { Resolution } \Delta \lambda / \lambda \\
(\mathrm{FWHM})\end{array}$ \\
\hline $\mathrm{Nd}(0.8 \mathrm{wt} \%), \mathrm{L} \alpha$ & 1.2 & $3.9(4.4)^{1}$ & \\
$\mathrm{Cs}(0.5 \mathrm{wt} \%), \mathrm{L} \alpha$ & 1.45 & $2.7(3.9)^{1}$ & \\
$\mathrm{Pu}(1 \mathrm{wt} \%), \mathrm{M} \beta$ & 1.95 & $2.9(5.0)^{1}$ & $\approx 0.0037(12 \mathrm{eV})$ \\
$\mathrm{U}(80 \mathrm{wt} \%), \mathrm{M} \alpha$ & 79 & 255 & \\
$\mathrm{Ru}(0.35 \mathrm{wt} \%), \mathrm{L} \alpha$ & $\approx 2.2$ & $\approx 1.5$ & \\
$\mathrm{Zr}$ in Zircaloy-2, L $\alpha(98 \mathrm{wt} \% \mathrm{Zr})$ & $205 / \mathrm{-}^{2}$ & $135 / 170^{2}$ & \\
\hline
\end{tabular}

${ }^{1}$ Yield after interference correction, in brackets gross yield.

${ }^{2}$ Yields on different spectrometers opposite to each other.

analysis which has to measure also very low concentrations the accelerating voltage is therefore typically set to $15-20 \mathrm{kV}$ to achieve acceptable counting and exposure times.

\subsection{SEM resolution}

High resolution surface topography of fuel must usually be made with a SEM [9-14]. Fine grain structure in high burn-up fuel zone can now also be displayed with this FEG EPMA with a resolution of $10-20 \mathrm{~nm}$ for pore observation (figure 9). In this context tests are underway with a tilt (maximum 200) and rotary sample holder for fractography. As the focus is on surface imaging it has only a small shielding ring around the sample holder. Only samples with a contamination free surface can be accepted.

\subsection{X-ray mapping}

Elemental mapping is widely used to record phase distribution and elemental agglomerations in the examination of irradiated materials (e.g., $[3,7,8,11,14])$. For precipitates and interfaces sub micron resolution is often requested.

4.2.1. Fuel surface. Figures $10 \mathrm{a}$ and $10 \mathrm{~b}$ show the start of grain re-crystallisation (SEM images) in high burn-up zones of a MOX fuel with the intermetallic precipitation of $4 \mathrm{~d}$ elements in the range of 0.1 to $0.2 \mu \mathrm{m}$ at grain faces. The $\mathrm{Ru}$ maps were acquired in only half an hour for $256 \mathrm{x} 256$ pixels with a beam of $20 \mathrm{kV}$ and $350 \mathrm{nA}$ resulting in a spatial X-ray resolution in the order of $0.3 \mu \mathrm{m}$ even under these stringent beam conditions.

Figure 10c acquired with the same conditions as before shows the precipitation of fission products in the form of oxides ( $\mathrm{Ba}, \mathrm{Cs}, \mathrm{Mo})$ and especially the accumulation of $\mathrm{Ba}(\mathrm{Cs})$ at fuel grain boundaries with an apparent concentration of $1-3 \mathrm{wt} \%$. The semi-quantitative mappings are the result from further evaluation by quantitative point analysis taking into account the interference of $U$ on Ba when present (figure 8, [15]) but not the local height variation and the related shadow effects. In this case they are of minor importance as they do not determine the basic element pattern.

Figure 11 shows the precipitation of Am and the fission product $\mathrm{Ba}$ at grain boundaries of an irradiated inert matrix fuel revealed also by the phase contrast of the backscattered electron image (BSE).

4.2.2. Zircaloy-2 rod. Secondary phase particles (SPPs) in the zircaloy base metal, which are in the size range of $0.1-0.3 \mu \mathrm{m}$, are improving the corrosion resistance. Density, size and elemental ratios also have an influence on the undesirable hydrogen uptake during the corrosion process. Transmission 

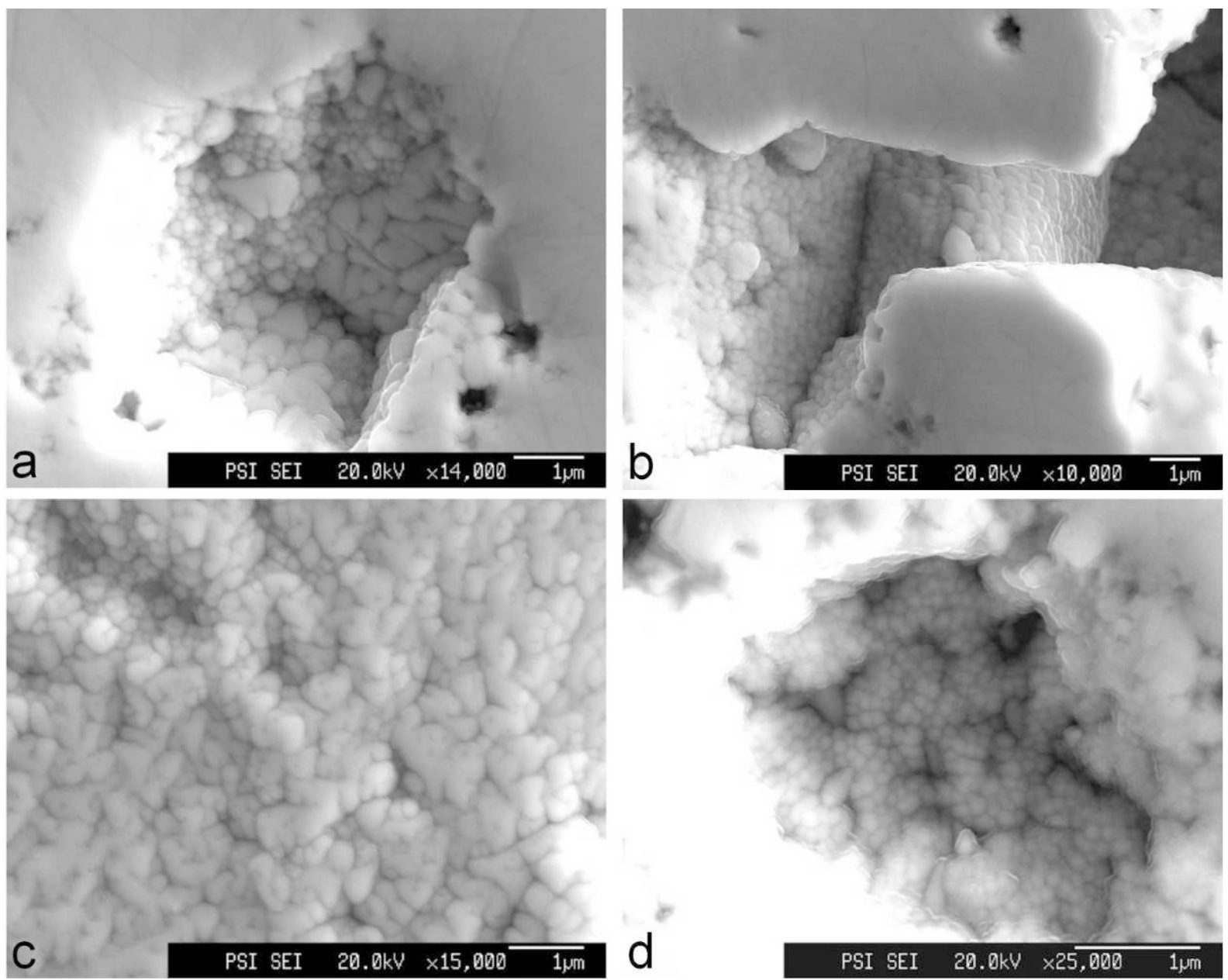

Figure 9. SEM from shielded FEG EPMA. Development of grain subdivision in high burn-up $\mathrm{UO}_{2}-$ fuel zone (a-c) and fully subdivided grains of $0.1-0.2 \mu \mathrm{m}(\mathrm{d})$.

electron microscopy (TEM), SEM-EDS [16], and Auger microprobe [17] have been used for examination requiring often extensive sample preparation. Wide local examinations by FEG EPMA $\mathrm{X}$-ray mappings give information about the state and local distribution of the SPPs during irradiation and its dissolution. Figure 12 shows local elemental mappings on a rod cross-section by an ad hoc measurement. Lower voltage with much longer acquisition time would be needed in a diligent survey. Oxide deposits on fuel rods (CRUD). In boiling water reactors deposits from suspended particles and solutes are formed on the fuel rods up to some micrometres [18]. It can have a detrimental influence on the fuel rod behaviour through decrease in thermal conductivity and if flaked off can contaminate the coolant system. It is desirable to know its composition for possible change in water chemistry. The BSE image in figure 13 shows there are at least two phases. Spot quantitative analysis revealed they are made up of pure hematite and mixed ferritic spinel phases. The applied $\mu$-XRD method [19] confirmed that the spinels are composed of $\mathrm{Zn}$-ferrite on the one hand and where other $3 \mathrm{~d}$ metal ions are incorporated a franklinite type spinel is formed. The quality of the semi-quantitative mappings (figure 13), measured with $15 \mathrm{kV}$ and $220 \mathrm{nA}$ in half an hour for each element, allows assessing the fraction of the different phases.

To complete the information the corresponding signal efficiencies for CRUD measurements on the spectrometer with LIF crystal are given on table 3 . 

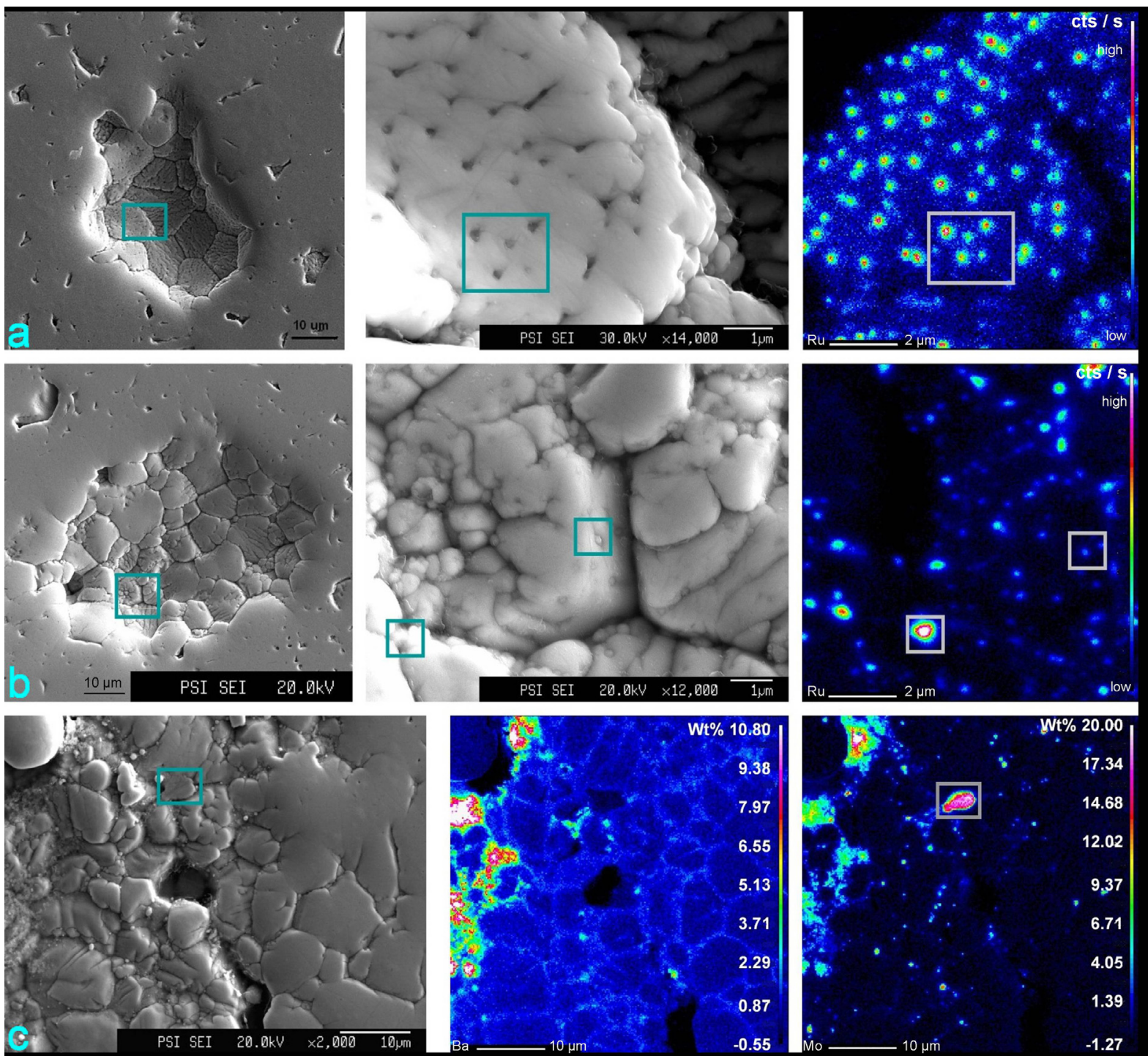

Figure 10. SEM and X-ray mappings of MOX fuel. Series a-b of high burn-up zone with start of grain subdivision and precipitation of intermetallic fission products $(\mathrm{Ru}, \mathrm{Rh}, \mathrm{Mo}, \mathrm{Pd}, \mathrm{Tc})$. Serie $\mathrm{c}$ : Precipitation of fission product oxides (Ba, Mo, a.o.) in the fuel and at grain boundaries (semiquantitative mappings; to note that height variations and shadow effects are not corrected).

Table 3. Spectrometer efficiency (LIF) for oxide deposits on irradiated Zircaloy-2 rod (CRUD) with fuel, equiv. $5 \mathrm{GBq}^{137} \mathrm{Cs} ; 50 \mathrm{mGy} / \mathrm{h}$ in $0.1 \mathrm{~m}$. Condition: $15 \mathrm{kV}, 350 \mathrm{nA}$.

\begin{tabular}{|c|c|c|}
\hline \multicolumn{3}{|c|}{ Jeol 8500F shielded / LIF crystal (Xe counter) } \\
\hline Element (wt\%) & Peak/BG-ratio & Yield at $15 \mathrm{kV}(\mathrm{c} / \mathrm{s} / \mathrm{nA})$ \\
\hline $\mathrm{Fe}$ in $\mathrm{Fe}_{2} \mathrm{O}_{3}, 70 \mathrm{wt} \% \mathrm{Fe}$ & 82 & 145 \\
\hline $\mathrm{Zn}$ in $\mathrm{ZnFe}_{2} \mathrm{O}_{4}, 27 \mathrm{wt} \% \mathrm{Zn}$ & 8.8 & 40 \\
\hline $\mathrm{Fe}$ in $\mathrm{ZnFe}_{2} \mathrm{O}_{4}, 46 \mathrm{wt} \% \mathrm{Fe}$ & 56 & 92 \\
\hline
\end{tabular}




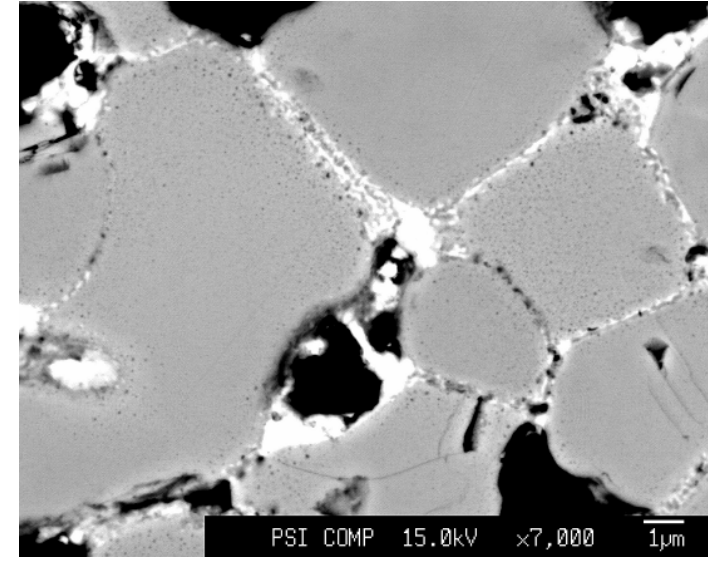

Figure 11. SEM and phase contrast BSE-images with X-ray mappings showing precipitation of amongst others $\mathrm{Am}$ and the fission product $\mathrm{Ba}$ at grain boundaries in an irradiated inert matrix fuel (semi-quantitative).
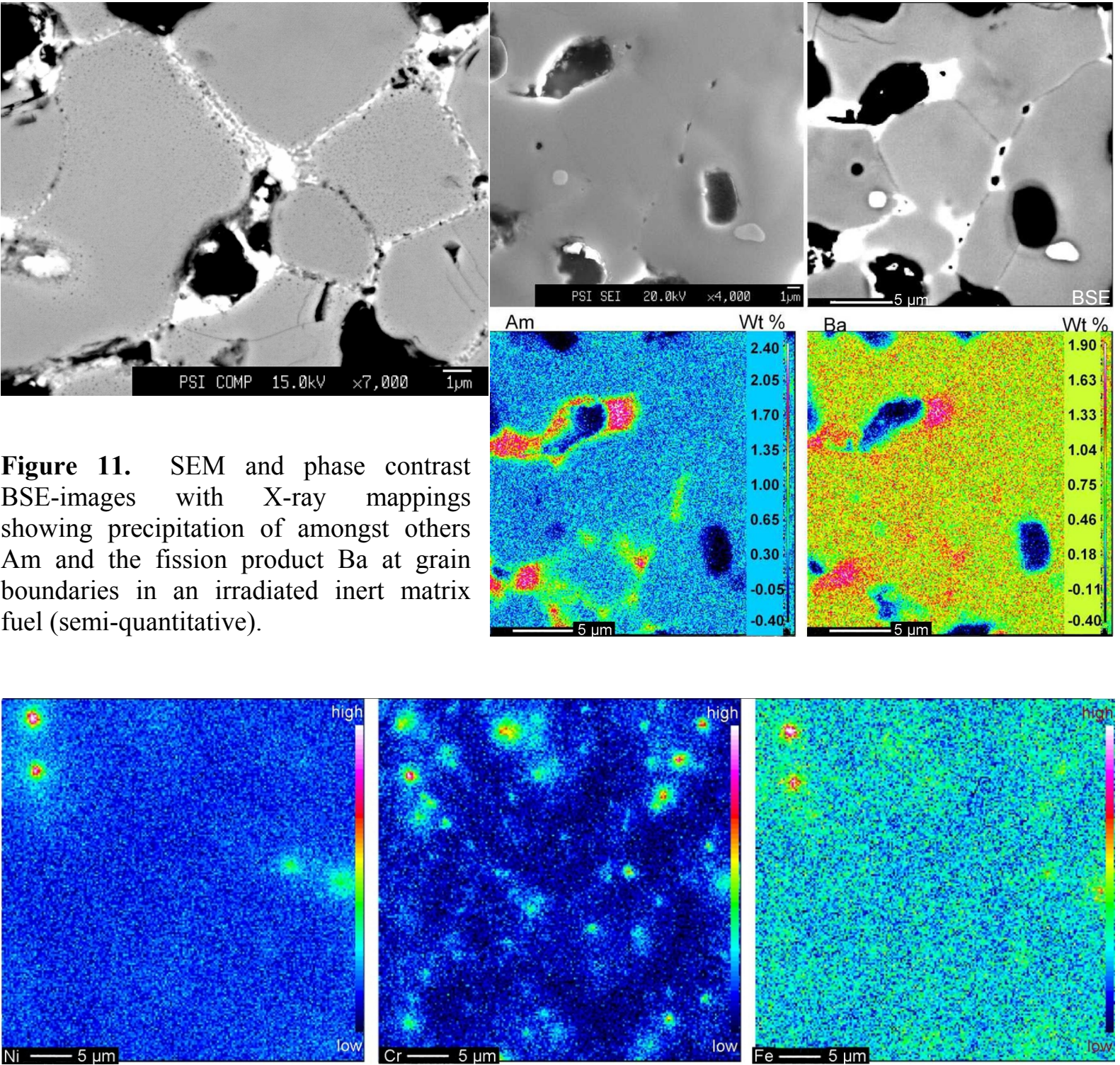

Figure 12. X-ray mappings of secondary phase particles in irradiated Zircaloy-2 rod known to be made up of $\mathrm{Zr}_{2}(\mathrm{Fe}, \mathrm{Ni})$ and $\mathrm{Zr}(\mathrm{Fe}, \mathrm{Cr})_{2}$ are partly distinguishable. Particle sizes on mappings comparable with actual size of 0.1 to $0.3 \mu \mathrm{m}$. Particles just below surface also detected. Fe partly dissolved in the base metal. Beam condition: $20 \mathrm{kV}, 450 \mathrm{nA}, 200$ x 200 pixels, $85 \mathrm{~ms} /$ pixel.

\section{Conclusion}

The performance goal by modifying and shielding a FEG EPMA for the microanalysis of high active materials has been realized. The radiation background could be reduced to a level that the spectrometer efficiencies allow to quantitatively measure the composition of nuclear materials down to very low element concentrations in an even smaller micro-area. 

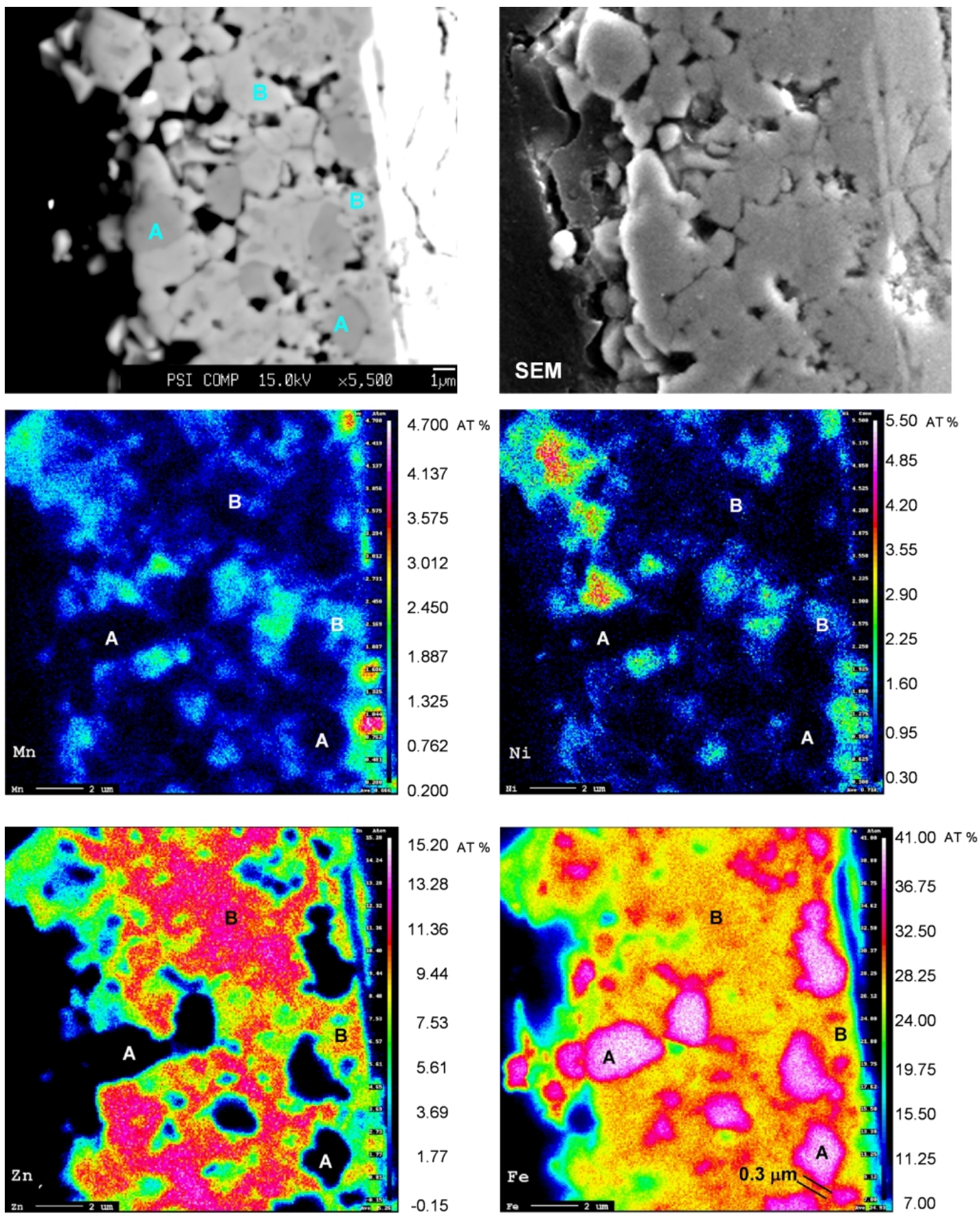

Figure 13. BSE-, SEM- and semi-quantitative X-ray images of oxide deposits on fuel rods (CRUD). A: hematite; B: spinels. Note: Mn, Zn, Fe with LIF crystal (Ka-lines), Ni with TAP crystal (L $\alpha$-line).

The quality of SEM and BSE imaging at high magnification is considerably improved and can only be reached with a SEM so far. Fractography is possible although SEM will stay the first choice. As there is no containment for the instrument only specimens with 'clean' surfaces can be accepted for examination to avoid contamination to spread.

The X-ray resolution is increased down to sub micrometre range thanks to small probe diameter and particularly high beam density. An examination of surface details such as precipitates and 
interfaces with elemental X-ray mapping is straightforward and reduces the need to apply other methods and/or extensive sample preparation. Alternatively faster acquisition is possible.

In operation one must be aware of the compact design with higher radiation impact on some of the delicate components such as crystals and detectors. This requires amongst others faster acquisition also to reduce possible spreading of volatile active nuclides which again often affords a higher beam voltage to increase the detection limits.

\section{Acknowledgments}

We wish to thank for the good collaboration with the manufacturers of Jeol Germany and remX $\mathrm{GmbH}$ and our Hotlab operating group to make this project a success and especially M. Mostert, remX for getting all well done and J. Börder, A. Neumann, Th. Königs, Jeol to get it all run.

\section{References}

[1] Kleykamp H 1979 J. Nucl. Mater. 8013

[2] Walker C T 1979 J. Nucl. Mater. 80190

[3] Brémier S, Chareau J M and Walker C T 2006 EMAS 2006 - 7th Regional Workshop on Electron Microanalysis Today (Karlsruhe, Germany; 13-16 May 2006)

[4] Pearce J H, Summerling R and R. Hargraves R 1983 J. Nucl. Mater. 1161

[5] Lamontagne J, Desgranges L, Valot C, Noirot J, Blay Th, I. Roure I and B. Pasquet B 2006 Microchim. Acta 155183

[6] Verwerft M 2000 J. Nucl. Mater. 28297

[7] Perrot M 1995 Thèse - Diplôme Universitaire Supérieur de Recherche. (Paris: Université Paris Sud) UFR scientifique d'Orsay, préparé au CEA/CEN de Saclay, 29. sept. 1995

[8] Restani R, Martin M, Kivel N and Gavillet D 2009 J. Nucl. Mater. 385435

[9] Une K, Nogita K, Kashibe S and Immamura M 1992 J. Nucl. Mater. 18865

[10] Walker C T, Kameyama T, Kitajima S and Kinoshita M 1992 J. Nucl. Mater. 18873

[11] Fisher S B, White R J, Cook P M A, Brémier S, Corcoran S R C, Stratton R, Walker C T, Ivision P K and Palmer I D 2002 J. Nucl. Mater. 306153

[12] Manzel R and Walker C T 2002 J. Nucl. Mater. 301170

[13] Spino J, Stalios A D, Santa Cruz H and Baron D 2006 J. Nucl. Mater. 35466

[14] Noirot J, Desgranges L and Lamontagne J 2008 J. Nucl. Mater. 372318

[15] Kleykamp H 1981 Z. Naturforsch. 36a 1388

[16] Proff C, Abolhassani S and Lemaignan C 2011 J. Nucl. Mater. 416125

[17] Hatano Y and Sugisaki M 1996 J. Nucl. Sci. Technol. 33829

[18] Uchida S, Asakura Y, Ohsumi K, Miki M, Aizawa M, Matsushima Y and Yonezawa K 1987 J. Nucl. Sci. Technol. 24385

[19] Orlov A, Restani R, Kuri G, Degueldre C and Valizadeh S 2010 Nucl. Instrum. Methods B 268 297 